\section{Trabecular variant of juvenile aggressive ossifying fibroma of anterior mandible}

\author{
Manjunatha B.S., ${ }^{1}$ Nagarajappa Das, ${ }^{2}$ \\ Saraswati Naik, 3 Gowramma R. ${ }^{4}$ \\ 1Department of oral and maxillofacial \\ Pathology, KM Shah Dental College and \\ Hospital, Vadodara; 2Department of Oral \\ and Maxillofacial Surgery, ${ }^{3}$ Department \\ of Pedodontics and Preventive Dentistry \\ and 4Department of Periodontics, SJM \\ Dental College and Hospital, Karnataka, \\ India
}

\section{Abstract}

Juvenile ossifying fibroma (JOF) is an expansile intra-osseous lesion of the jaw that emulate odontogenic lesions frequently seen in patients under 15 years of age. They are histologically characterized by the presence of fibrous stromal cells along with mineralized tissues. Clinically, these are characterized by early age of onset, histological patterns, high rate of recurrence and the aggressive local behavior. The differential diagnosis of JOF with other fibro-osseous lesions of the jaw should be made along with an essential microscopic examination and be largely based on the character of the calcified products of the tumor. The purpose of this article is to present a rare clinical case of the trabecular type of JOF and to describe its clinical, radiological and histological characteristics. The clinician should be aware of this type of lesion in order to be able to distinguish this it from other fibrous lesions if encountered in routine practice and for appropriate treatment to be carried out.

\section{Introduction}

Juvenile ossifying fibroma (JOF) is an uncommon fibro-osseous lesion mostly occurring in the facial bones. ${ }^{1}$ The maxilla is more commonly involved than the mandible. ${ }^{2}$ The term juvenile emphasizes that the tumor largely develops in younger individuals, $79 \%$ of whom are under the age of 15 years old. ${ }^{3}$ It has been recognized as a separate histopathological entity among the fibroosseous group of lesions which are highly aggressive in nature and which have a strong trend of recurrence.

The tumor can grow rapidly, expanding in the affected area. Therefore, they are also referred to as active or aggressive ossifying fibromas. ${ }^{4}$ Two histopathological variants of JOF have been recognized as trabecular JOF and psammomatoid JOF. 5 However, the two categories also have a distinct predilection for specific age-groups: the average age of occurrence of the trebacular type is 8.5-12 years, whereas that of the psammomatoid type is 16-33 years. One clinical feature that helps in differentiating the trebacular form and psammomatoid types of JOF is the site of involvement. The psammomatoid type of JOF occurs mainly in the paranasal sinuses and the trebacular type occurs mainly in the maxilla. ${ }^{5}$ Mandibular and extracranial involvement are rare. 4

Here we report a case of trabecular type of JOF in a 7-year old male patient with a complaint of swelling in the front region of the lower jaw of one month duration.

\section{Case Report}

A 7-year old boy was referred by a general dentist to the Department of Oral and Maxillofacial Surgery in May 2011 for a localized swelling in the anterior mandibular area of one month duration. The patient also reported difficulty in closing his mouth, in speech and eating because of the lesion. The extra-oral clinical examination revealed a swelling of the outer cortical layer at the anterior mandibular incisor area (Figure 1) which produced slight facial asymmetry. It was painless to palpation. The swelling was firm to slightly hard in consistency and measured approximately $2 \times 2 \mathrm{~cm}$ (Figure 2). Both permanent center incisor teeth were displaced or had drifted laterally due to the lesion. The occlusal and intra oral periapical radiographs revealed radiolucent mass at the anterior mandibular area and both central incisors had drifted laterally (Figure 3).

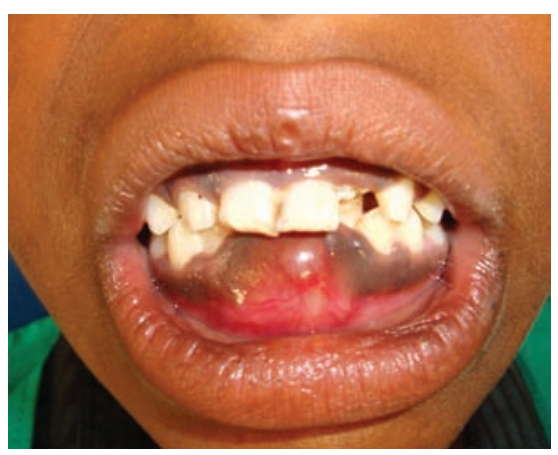

Figure 1. Clinical photograph showing the swelling in the mandibular anterior region.
Correspondence: Manjunatha BS, Department of oral and maxillofacial Pathology, KM Shah Dental College and Hospital, Sumandeep Vidyapeeth, Pipariya-391760, Vadodara, India.

Tel. +91.02668.245266 - Fax: +91.02668.245292

E-mail: drmanju26@hotmail.com

Key words: active, aggressive, fibro-osseous lesion, juvenile ossifying fibroma, psammomatoid, trabecular.

Conflict of interests: the authors report no potential conflict of interests.

Received for publication: 14 March 2012.

Revision received: 9 May 2012

Accepted for publication: 18 May 2012.

This work is licensed under a Creative Commons Attribution NonCommercial 3.0 License (CC BYNC 3.0).

(C) Copyright B.S. Manjunatha et al., 2012

Licensee PAGEPress, Italy

Pediatric Reports 2012; 4:e24

doi:10.4081/pr.2012.e24

Based on the clinical and radiographic features, diagnosis of ossifying fibroma was made and the lesion was removed by surgical curettage under local anesthesia. The surgical specimen contained both soft and hard tissues (Figure 4). The histopathological examination of specimen revealed a cellular connective tissue of mesenchymal nature, composed of numerous bundles of collagen fibers associated with proliferating round to stellate shaped fibroblasts (Figure 5) with bone trabeculae and osteoid (Figure 6). In a few areas, darkly stained multinucleated giant cells were noted (Figure 7). Peripheral bony trebaculae was lined by osteoblasts. This led us to make a diagnosis of trabecular juvenile ossifying fibroma.

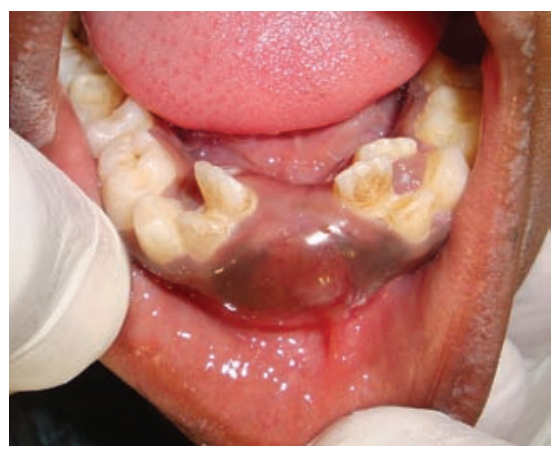

Figure 2. Photograph showing ovoid, firm, intra oral swelling, measuring about $2 \times 2 \mathrm{~cm}$ in relation to mandibular incisor area causing lateral displacement of both central incisors. 


\section{Discussion}

JOF has characteristics that distinguish it from the adult variant and are related to early age of onset, localization of the tumor, clinical behavior and microscopic appearance, and a trend for recurrence. ${ }^{2}$ About $79 \%$ of JOF occurs in children under 15 years of age. ${ }^{3}$ Few authors have described that the maxilla is the most frequently affected site.6,7 Johnson et al. reported that $90 \%$ of JOF occur in the paranasal sinuses and only $10 \%$ in the mandible. ${ }^{4}$ According to a recent article, very few cases of mandibular JOF have been reported in the English Language literature. ${ }^{8}$

The histogenesis of the ossifying processes in JOF seems to have two possible origins: i) the excessive proliferation of periodontal ligaments; and ii) a metaplastic process occurring in the connective tissue fibers (non-periodontal in origin). ${ }^{9}$

The periodontal origin is being more common. ${ }^{9}$ A recent report by Pimenta et al. ${ }^{10}$ has shown the association of a new tumor suppressor gene HRPT2 mutation with ossifying fibroma and suggested that these lesions may arise as a result of haploinsufficiency of the HRPT2 gene.

Although in the past JOF has been described as a variant of ossifying fibroma, more recently it is segregated into trabecular (TrJOF) and psammomatoid (PsJOF) subtypes with varied clinical and histological features. ${ }^{5}$

Trabecular variant of JOF was earlier described by Reed and Hagy in 1965 under JOF. 5

Trabecular JOF is distinguished by the presence of trabeculae of fibrillar osteoid and woven bone and psammomatoid JOF is characterized by the presence of small uniform spherical ossicles that resemble psammoma bodies. ${ }^{5}$

Trabecular JOF is a gnathic lesion affecting the jaws and has a predilection for the maxilla.5,11 Few cases of TrJOF affecting the mandible have been reported and in the mandible, the ramus-molar area is the most common site. ${ }^{11}$ The case presented here highlights one such rare case occurring in the mandibular anterior region, therefore, documentation of such a rare clinical case of TrJOF making it a familiar entity to clinicians.

However, the two categories of JOF also have a distinct predilection for specific age groups. The average age of occurrence of TrJOF is 8.5-12 years. The most important clinical finding that helps to differentiate $\mathrm{TrJOF}$ from PsJOF is the site of involvement, with PsJOF occurring mainly in the paranasal sinuses and TrJOF occurring mainly in the maxilla. ${ }^{5}$

The microscopic features of the lesion are unique and comprise a cell-rich fibrous connective tissue stroma containing areas of osteoid, trabeculae of woven bone interspersed with spindle to polyhedral shaped fibroblast cells. $5,6,12$

In 1983, Makek published the largest series of TrJOF and reviewed 24 cases. ${ }^{13}$ The results showed a slight male predilection (1.3:1) with maxilla being more frequently affected. Slootweg et al. ${ }^{14}$ reported 10 cases showing a mean age of 11.8 years, yet again showing a male dominance with $60 \%$ of the cases occurring in the maxilla. In the complex case presented here, a multidisciplinary evaluation
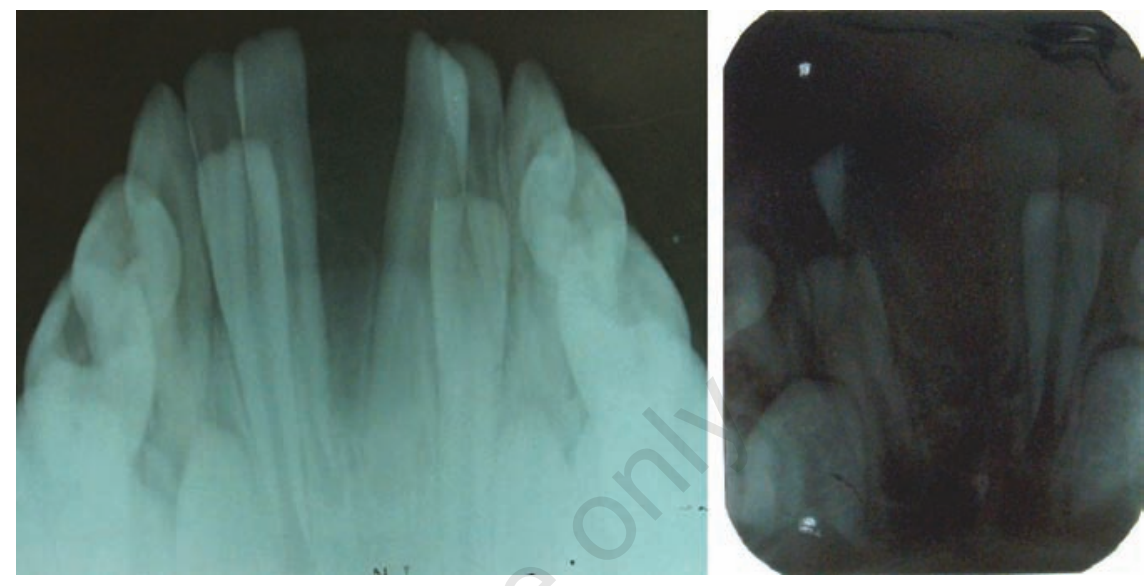

Figure 3. Occlusal and IOPA radiographs revealed a radiolucent mass in the mandibular incisor area displacing 31 and 41 laterally and resorbing the buccal cortical plate of the mandible.

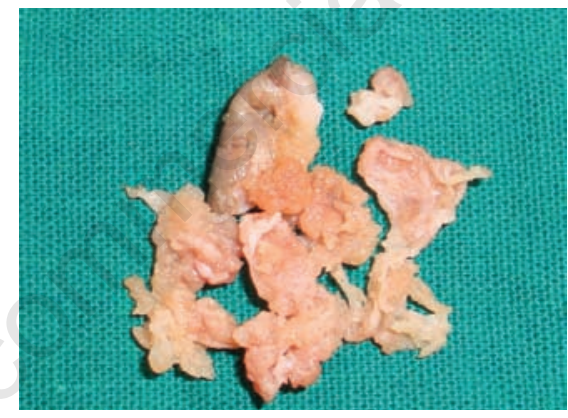

Figure 4. The macroscopic appearance of the lesion treated by surgical curettage.

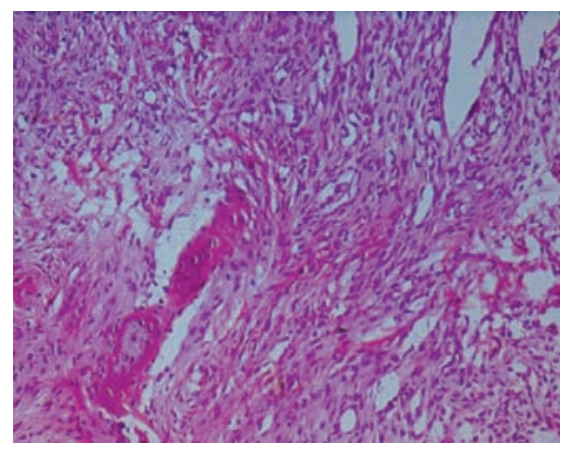

Figure 6. Photomicrograph showing tumor mass comprised of proliferation of spindle cells with irregular osteoid, rimmed by osteoblasts (Haematoxylin and Eosin, $400 \times$ magnification).

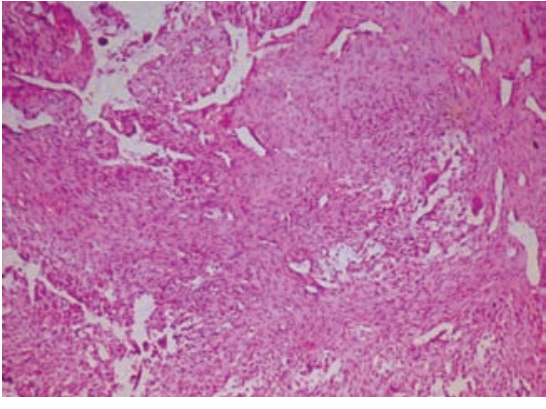

Figure 5. Photomicrograph showing fibrocellular connective tissue with stellateshaped plump fibroblasts (Haematoxylin and Eosin stain, $40 \times$ magnification).

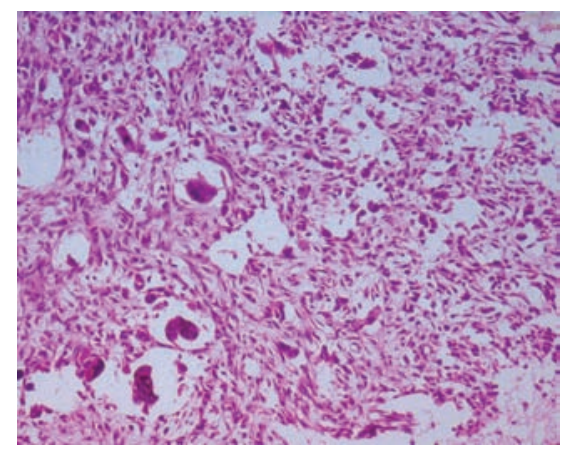

Figure 7. Photomicrograph showing fibrocellular mesenchymal tissue and few multinucleated giant cells (Haematoxylin and Eosin, 200× magnification). 
with careful assessment of clinical, radiographic and histopathological features was necessary in order to arrive at a correct diagnosis and identify the most appropriate therapeutic approach. Therefore, a team comprising oral and maxillofacial surgeon, pedodontist, oral pathologist and periodontist given rendered without any recurrence.

Aggressive JOF require the complete surgical excision, en bloc or hemisection to prevent recurrence. JOF has a tendency of aggressive growth and recurrence is also documented, ranging from a rate of $30-58 \% .7,15,16$

In summary, juvenile ossifying fibroma is a rare benign fibro-osseous tumor that occurs in infants and children. It is locally aggressive and shows high recurrence. Therefore, these lesions are to be recognized and managed early.

\section{Conclusions}

To conclude, this paper presents a challenging and a unique case of trabecular JOF in a 7year old male occurring in the anterior part of mandible, mimicking a benign/reactive lesion.

\section{References}

1. Slootweg PJ. Maxillofacial fibro-osseous lesions: classification and differential diagnosis. Semin Diagn Pathol 1996;13: 104-12.

2. Waldron CA. Bone Pathology. In: Neville BW, Damm DD, Allen CM, Bouguat JE. Oral and maxillofacial pathology. Philadelphia: WB Saunders; 1995. pp 443-92.

3. Slootweg PJ, Muller H. Juvenile ossifying fibroma: report of four cases. J Craniomaxillofac Surg 1990;18:125-9.

4. Johnson LC, Yousefi M, Vinh TN, et al. Juvenile active ossifying fibroma. Its nature, dynamics and origin. Acta Otolaryngol 1991;488:1-40.

5. El-Mofty S. Psammomatoid trabecular juvenile ossifying fibroma of the craniofacial skeleton: Two distinct clinicopathologic entities. Oral Surg Oral Med Oral Pathol Oral Radiol Endod 2002;93:296-304.

6. Slootweg PJ, Panders AK, Koopmans R, Nikkels PG. Juvenile ossifying fibroma. An analysis of 33 cases with emphasis on histopathological aspects. J Oral Pathol Med 1994;23:385-8.

7. Makek MS. So-called fibro-osseous lesions of tumor origin. Biology confronts terminology. J Craniomaxillofac Surg 1980;18: 57-72.

8. Leimola-Virtanen R, Vaheatalo K, Syrjanen S. Juvenile active ossifying fibroma of the mandible: a report of two cases. J Oral Maxillofac Surg 2001;59:439-4.

9. Ono A, Tsukamoto G, Nagatsuka H, et al. An immunohistochemical evaluation of
BMP-2, -4, osteopontin, osteocalcin and PCNA between ossifying fibromas of the jaws and peripheral cemento-ossifying fibromas on the gingiva. Oral Oncol 2007; 43:339-44.

10. Pimenta FJ, Gontijo Silveria LF, Tavares GC, et al. HRPT2 gene alterations in ossifying fibroma of the jaws. Oral Oncol 2006;42:735-9.

11. Saiz-Pardo-Pinos AJ, Olmedo-Gaya MV, Prados-S nchez E, Vallecillo-Capilla M. Juvenile ossifying fibroma: A case study. Med Oral Patol Oral Cir Bucal 2004;9:4548.

12. Williams HK, Mangham C, Speight PM. Juvenile ossifying fibroma: an analysis of eight cases and a comparison with other fibro-osseous lesions. J Oral Pathol Med 2000;29:13-8.

13. Makek M. Clinical pathology of fibro-osteocemental lesions of craniofacial skeleton and jaw bones. Basel, Switzerland: Karger; 1983. pp. 128-227.

14. Sun G, Chen X, Tang E, et al. Juvenile ossifying fibroma of the maxilla. Int $J$ Oral Maxillofac Surg 2007;36:82-5.

15. Hall EH, Naylor GD, Moler RW, Warnock GR. Early aggresive cement-ossifying fibroma: a diagnostic and treatment dilemma. Oral Surg Oral Med Oral Pathol 1987; 63:132-6.

16. Zupi A, Ruggiero AM, Insabato L, et al. Aggressive cemento-ossifying fibroma of the jaws. Oral Oncol 2000;36:129-33. 